\title{
OS RUMOS DA EDUCAÇÃO EM QUESTÃO: DA “HEGEMONIA ÀS AVESSAS” À CRISE DE HEGEMONIA
}

\author{
EL CAMINO DE LA EDUCACIÓN EN PREGUNTA: DE LA "HEGEMONÍA A LA \\ INVERSA" A LA CRISIS DE LA HEGEMONÍA
}

\section{THE WAY OF EDUCATION IN QUESTION: FROM “HEGEMONY IN REVERSE” TO CRISIS OF HEGEMONY}

DOI: http://dx.doi.org/10.9771/gmed.v12i1.34757

\begin{abstract}
Zuleide Simas da Silveira ${ }^{1}$
Resumo: Este texto busca evidenciar os traços de continuidade e descontinuidade entre os sucessivos mandatos de governos neoliberais, no Brasil, dos anos 1990 até os dias que correm, e suas implicações no campo educacional. Para cumprir com desafio, emprega categorias analíticas como capitalismo dependente, fascismo dependente, hegemonia às avessas e crise de hegemonia, tendo como mediações as ações governamentais em torno das políticas macro e microeconômicas, apontando para a contínua perda de direitos sociais e subjetivos da classe trabalhadora e para os processos de privatização e mercadorização da educação.
\end{abstract}

Palavras-chave: Capitalismo dependente; Contrarreformas; Educação pública.

Resumen: Este texto tiene como objetivo resaltar los rasgos de continuidad y discontinuidad entre los mandatos sucesivos de los gobiernos neoliberales en Brasil desde la década de 1990 hasta la actualidad, y sus implicaciones en el campo educativo. Para enfrentar el desafío, emplea categorías analíticas como capitalismo dependiente, fascismo dependiente, hegemonía atrasada y crisis de hegemonía, mediadas por acciones gubernamentales en torno a políticas macro y microeconómicas, que apuntan a la pérdida continua de los derechos sociales y subjetivos de la clase trabajadora. y para los procesos de privatización y mercantilización de la educación.

Palabras clave: capitalismo dependiente; Contrarreformas; Educación publica.

Abstract: This text aims to highlight the continuity and discontinuity traits between the successive mandates of neoliberal governments in Brazil from the 1990s to the present day, and their implications in the educational field. To meet the challenge, it employs analytical categories such as dependent capitalism, dependent fascism, backward hegemony and crisis of hegemony, mediated by governmental actions around macro and microeconomic policies, pointing to the continuous loss of social and subjective rights of the working class. and for the processes of privatization and commodification of education.

Keywords: Dependent capitalism; Counterreforms; Public education.

\section{Introdução}

O capitalismo contemporâneo, em sua fase neoliberal, vem marcado predominantemente pelos seguintes elementos: a) internacionalização da economia, com base na geopolítica, a partir da integração dos Estados-Nações aos mercados comum, regional e global, bem como dos avocados acordos comerciais que se originam dessa relação; b) ampliação da internacionalização produtiva, iniciada no século XIX e aprofundada após a Segunda Guerra Mundial, com base na crescente capacidade das transnacionais em 
conectar mercados e transportar capital e tecnologia entre fronteiras nacionais; c) reconfiguração da divisão internacional do trabalho a partir da participação de países do antigo bloco socialista e da incorporação daqueles do Leste Asiático; d) interpenetração das atividades do setor de serviços com as dos setores primário e secundário da economia; e) desemprego estrutural, acompanhado da superexploração, expropriação e espoliação do trabalho; f) modificação do papel do Estado na sua relação com o trabalho e a educação; g) manutenção da brecha científico-tecnológica-educacional-cultural entre países de capitalismo central e dependentes; h) estratégias, por parte do empresariado, de produção do consenso em torno do empreendedorismo, voluntariado e responsabilidade social (SILVEIRA, 2011, p. 135-136).

No que diz respeito à relação metabólica entre o homem e natureza, que põe em risco a sobrevivência de todas as espécies de seres vivos,

[...] agências estatais, empresas privadas e mesmo algumas organizações não governamentais mais pragmáticas, trabalham nos marcos de uma sustentabilidade conservadora, produzindo discursos e práticas oficiais, valorizando noções científicas e técnicas, como se fossem neutras, tratando os mecanismos de gestão ambiental (conselhos, leis, selos e mercadorias verdes) como um campo da ação preferencial de especialistas, consequentemente desvalorizando a participação mais efetiva da população (BARRETO, 2019, p. 63-64).

No plano educacional, aprofundam-se os processos de privatização e mercadorização da educação, em todos os níveis e modalidades de ensino, seguidos de severos ataques à educação e aos e profissionais da educação de pensamento crítico, particularmente aos da rede pública de ensino.

Sendo uma forma de relação social que envolve diferentes sujeitos (homens, mulheres, jovens e crianças), de carne e osso, segundo as classes sociais e respectivas frações de classe, gênero, etnia, raça e naturalidade, o capitalismo possui uma especificidade tal, no Brasil, que se manifesta de modo dependente, associado, subordinado, exportador, concentrador e excludente (BRUM, 1982; FERNANDES, 1973; IANNI, 1982, 1988; MARINI, 1993, 1997, 2000; SANTOS, 1998, 2018).

Esta relação entre dominação e subordinação capitalista, apresenta seus desdobramentos em todas as dimensões da sociedade (desde o controle da natalidade, planejamento e regulação familiar, passando pela informação, comunicação e o consumo e lazer de massa, até a educação, compra de pacotes tecnológicos e mobilidade de trabalhadores, pesquisadores docentes e discentes). Ela se desenvolve por mediação do aparelho de Estado, particularmente a partir dos anos de 1970-1990, com a ascensão de forças políticas conservadoras e entreguistas, representadas por Augusto Pinochet (1973), Margareth Thatcher (1979), Ronald Reagan (1980), Helmut Kohl (1982) e Collor de Mello (1990).

Sob o famoso lema da Tina (There is no Alternative), o caráter predatório do capitalismo em sua fase neoliberal trata de promover a reestruturação do mundo do trabalho, a desregulamentação dos direitos trabalhistas, o desmantelamento do Sistema Único de Saúde, a contrarreforma da previdência ${ }^{2}$ e a contrarreforma da educação, de modo a inserir o país nos mercado internacional, sob as pautas da exportação comodificada e da reexportação de bens intermediários.

Se não há alternativa, a política macroeconômica a ser adotada por todo e qualquer governo tido como responsável, independentemente de sua filiação partidária, deve guardar coerência com os imperativos do Fundo Monetário Internacional (FMI), Banco Mundial, Organização Mundial do Comércio (OMC), 
Organização para a Cooperação e Desenvolvimento Econômico ou Económico (OCDE), Organização das Nações Unidas para a Educação, a Ciência e a Cultura (UNESCO) e os blocos político-econômicos regionais, como o Mercosul e a União Europeia, entre outros organismos supranacionais.

Isto quer dizer que, no Brasil, desde o governo Collor de Mello, a política macroeconômica não foi modicada, mas sim houve continuidade entre um mandato e outro, independentemente do partido político que esteve à frente do bloco no poder, fosse ele PRN, PSDB, PFL, PT, PMDB ou o atual PSL 3 .

A diferença entre um governo e outro encontra-se, pois, muito mais na execução das políticas microeconômicas. No entanto, as reformas ou contrarreformas dependem das especificidades das lutas de classe internas à cada país (GRAMSCI, 2001, CC. 11, \12, pp. 102; 2002, CC 19, \5, pp.38-40; CC. 25, \ 7 , pp.142-144). Basta observar as lutas travadas entre capital, por mediação do Estado (supranacional e nacional), educação, trabalho e saúde, no Brasil, desde os governos Collor de Mello e Itamar Franco, passando pelos mandatos de Fernando Henrique Cardoso, Lula da Silva, Dilma Rousseff, Michel Temer, até o atual Jair Bolsonaro.

Não sem razão, a privatização e a mercadorização da educação pública, no Brasil, não se concretizaram segundo os interesses dos dominantes. Ela vem sendo costurada a retalhos, devido ao enfrentamento do movimento classista de sindicatos combativos, à exemplo do Sindicato Nacional dos Docentes das Instituições de Ensino Superior (ANDES-SN) e do Sindicato Nacional dos Servidores Federais da Educação Básica, Profissional e Tecnológica (SINASEFE).

Neste contexto e nos limites deste texto, buscamos analisar alguns poucos traços de continuidade e descontinuidade entre um e outro governo. Mesmo sob o risco de deixar lacunas, privilegiaremos os períodos de governo a partir de 2003 até o presente histórico.

\section{A hegemonia às avessas}

Se nos três primeiros mandatos de governos neoliberais, a privatização clássica das riquezas naturais, dos serviços, indústrias e empresas estatais e o desmantelamento da educação pública se deu de forma aberta, espúria e à revelia do interesse público e da coisa pública, nos mandatos de amplas alianças Lula da Silva e Dilma Rousseff -, o desmonte da educação pública opera sobre contradições do bloco no poder, evidenciando seu compromisso com a austera política macroeconômica ao mesmo tempo em que, no plano da política microeconômica, se empenha em resolver as mazelas sociais.

De um lado, o processo de padronização dos instrumentos de avaliação foram implementados e as parcerias público-privadas tornaram-se diversificadas de tal maneira que: (i) o Movimento Todos pela Educação fez valer seus interesses de classe (empresarial/burguesa) nas três esferas de governo, por meio do Plano de Metas Todos pela Educação, combinando coerção e persuasão, em torno da direção das escolas das redes municipal e estadual de educação, cujos secretários se viram obrigados a elaborar o Plano de Ações Articuladas (PAR) como moeda de troca para receber assistência técnica e financeira do MEC; (ii) não diferente, a Associação Brasileira de Agronegócio (ABAG) mostrou-se eficaz (no sentido que o capital dá ao termo) nas ações junto a Conselhos de Educação, Secretarias de Educação, escolas das redes de pública 
e privada de ensinos, promovendo o consenso passivo de parcela significativa de professores e estudantes, por mediação do Programa Educacional Agronegócio na Escola, contando com o apoio do Ministério da Agricultura, Pecuária e Abastecimentos; (iii) por meio do Programa Universidade para Todos (PROUNI) e do Financiamento Estudantil (FIES), o aumento da oferta de matrículas, nas modalidades presencial e à distância, na rede privada de ensino superior aprofundou-se, beneficiando tanto os empresários do ensino, quanto o capital financeiro, por meio do crédito bancário4; (iv) a financeirização da educação, que não se confunde com o financiamento público da educação mas que dele se alimenta, se manifestou na aplicação de bolsa de valores (BM\&FBOVESPA) e comercialização de ações por parte de conglomerados educacionais como, o Kroton (Faculdade Anhanguera, Universidade Norte do Paraná e Pitágoras Faculdade); o Cruzeiro do Sul Educacional (Universidade Cruzeiro do Sul, Centro Universitário do Distrito Federal, Universidade Cidade de São Paulo, Faculdade Caraguá, Centro Universitário da Serra Gaúcha e Colégio Alto Padrão); o Ser Educacional (Universidade da Amazônia, Universidade de Guarulhos, Centro Universitário Maurício de Nassau, Centro Universitário Universus Veritas Faculdade Joaquim Nabuco, Faculdade Integrada do Tapajós,); o Anima (Faculdade São Judas Tadeu, Centro UNA, Centro Universitário Sociedade Educacional de Santa Catarina, Centro Universitário AGES, UniBH, HSM plataforma de Educação Corporativa, por meio da qual opera a HSM University ); o Laureate Education Inc. (Business School São Paulo, CEDEPE Business School, Centro Universitário FADERGS, Centro Universitário-FMU/FIAM-FAAM, Faculdade Internacional da Paraíba, Centro Universitário IBMR, Universidade Anhembi Morumbi, Universidade Salvador, Centro Universitário dos Guararapes, Centro Universitário Ritter dos Reis, Universidade Potiguar); o Adtalem Global Education (Damásio Educacional, IBMEC, Wyden Educacional), além da Estácio S.A, Universidade nove de Julho e Universidade Paulista UNIP5; (v) solidificou-se o arcabouço legislativo em torno da subsunção da política educacional e da política de ciência e tecnologia (C\&T) ao capital, por meio do Marco Legal de Ciência, Tecnologia e Inovação, Lei no 13.243/2016 — regulamentado pelo Decreto no 9283/2018 —, que veio aprofundar o processo de privatização da universidade e do patrimônio científico-tecnológico já iniciado pela Lei de Inovação, Lei no 10.973/2004; (vi) os fundos setoriais (FS), criados no governo FHC, pouco contribuíram para o financiamento da pesquisa básica; (vii) as decisões em torno das políticas de C\&T e de educação, tomadas à revelia do debate público por ministros de C\&T e de educação, mantiveramse em nível supranacional, no âmbito do MERCOSUL; (viii) no plano sociocultural, abre-se espaço para o empresariado transformar os saberes tradicionais e a cultura popular em fontes de lucro, com vistas ao "desenvolvimento local" e à formação do "capital humano".

De outro lado, ocorre: (i) a redistribuição de renda por meio do Bolsa Família e a continuidade do Programa de Geração de Renda e Emprego, entre outros programas sociais de caráter focalizado; (ii) a interiorização de universidades públicas e instituições da rede federal de educação profissional, científica e tecnológica, por meio da Reestruturação e Expansão das Universidades Federais (REUNI) e do Plano de Expansão da Rede Federal de Educação Profissional, respectivamente; (iii) a proliferação de cursos de qualificação; (iv) o aumento do emprego formal, ainda que, em sua maioria, voltado para o trabalho simples 
e precarizado; (v) a ampliação do crédito; (vi) a abertura de concurso público para diferentes setores da administração pública.

Com estas medidas, apesar do forte aparato policial e militar - sem o que o Estado democrático de direito burguês não se reproduz -, os onze primeiros anos de governo PT, foram marcados por significativos índices de aprovação. Graças ao regime de colaboração de classes, atendeu os diferentes interesses das frações da burguesia brasileira, sobretudo a do setor financeiro, ao mesmo tempo em que obtinha o consenso passivo de expressiva parcela das classes subalternas, sobretudo daquelas mais pobres, bem como o consentimento ativo das lideranças dos movimentos sociais.

Neste contexto, se constrói a "hegemonia às avessas" (OLIVEIRA, 2010). Tendo o programa Bolsa Família como pilar, a hegemonia às avessas, segundo o mestre da dialética ${ }^{6}$, foi um fenômeno marcadamente novo, pois que, não foi parecido com qualquer prática de dominação exercida ao longo da história da sociedade brasileira. Não foi patrimonialismo, patriarcalismo e tampouco populismo.

Oliveira aponta criticamente para pesquisadores do campo marxista-gramsciano que empunham bandeiras na defesa do Bolsa Família, como se ele fosse um grande programa de inclusão das classes dominada. De fato, igualdade socioeconômica não é o mesmo que igualdade de oportunidades; incluir no mercado não significa reduzir a concentração de riqueza; e, tampouco, exprime a incorporação de parcelas mais pobres da sociedade ao "grau mais estritamente político da consciência política coletiva" (GRAMSCI, 2007, v. 3, \ 17, p.41).

Funcional ao processo de internalização da economia, a dominação por meio da hegemonia às avessas inverte os termos gramscianos, de tal modo que,

[...] parece que, fisicamente, os dominados dominam, pois fornecem a 'direção moral' e até estão à testa das organizações do Estado, de modo direto ou indireto, e das grandes empresas estatais. Parece que eles são os próprios capitalistas, pois os grandes fundos de pensão das estatais são o coração do novo sistema financeiro brasileiro e financiam pesadamente a dívida interna pública. Parece que eles comandam a política, pois dispõem de poderosas bancadas na Câmara dos Deputados e no Senado. Parece que a economia está finalmente estabilizada, que se dispõe de uma sólida moeda e que tal façanha se deveu à política governamental, principalmente no primeiro mandato de Lula [da Silva] (OLIVEIRA, 2010, p. 26).

Como a aparência fenomênica esconde a sua essência e com ela não coincide, continua o mestre da dialética:

O consentimento sempre foi o produto de um conflito de classes em que os dominantes, ao elaborarem sua ideologia que se converte em ideologia dominante, trabalham a construção das classes dominadas à sua imagem e semelhança. Esse é o núcleo duro da elaboração de Marx e Engels em $A$ ideologia alemã (...) os dominados realizam a 'revolução moral' - derrota do apartheid na África do Sul e [re] eleição de Lula e Bolsa Família no Brasil [em 2006] - que se transforma e se deforma, em capitulação ante a exploração desenfreada (OLIVEIRA, 2010, p. 27. Negritos nossos).

É inegável que nos governos Lula da Silva e Dilma Rousseff houve alterações na pirâmide social brasileira, mas como classe antagônica ao capital, os trabalhadores mantiveram-se desorganizados e sem direção política, abrindo espaço para forças políticas ultraconservadoras acederem ao poder, baseadas no “ódio de classe” (RANCIERE, 2014). 


\section{A crise de hegemonia}

Se para o governo Lula da Silva a crise de 2008 foi uma "marolinha", o período Dilma Rousseff, particularmente o segundo, viu-se imerso na tormenta. Dando continuidade à aplicação da Lei de Responsabilidade Fiscal (LRF), sancionada por FHC, em 2000, o primeiro governo Dilma Rousseff foi marcado pelo ataque à autonomia universitária por meio da privatização dos hospitais universitários, que passam a ser geridos pela Empresa Brasileira de Serviços Hospitalares (EBSERH), e pela negligência com as pautas do movimento popular de junho de 2013, que reivindicava mais serviços públicos de qualidade (educação e saúde), transportes coletivos com "passe livre", mais participação no processo político e mais ações em torno da necessária redução das desigualdades sociais.

Os protestos expressavam o esgotamento do petismo e a correlata crise de hegemonia. Em resposta, a violência política com o emprego da Força Nacional e a aprovação da Lei antiterrorista que, aliada à estratégia de acumulação, articula expropriação, superpopulação relativa e exploração (FONTES, 2010; 2018). Neste quadro, a bipolarização entre PSDB e PT-PMDB já expressava uma crise política sobredeterminada, pois que se tratava de representar politicamente o mesmo bloco burguês, capitaneado pelo capital financeiro e suas alianças com as frações da indústria, dos serviços e do agronegócio.

Disputavam quem seguiria pagando os juros da dívida pública, concentrando renda, freando a reforma agrária, esfacelando os serviços públicos essenciais e retirando os direitos sociais subjetivos para garantir a taxa de lucro do capital (DEMIER, 2016, p.54).

O resultado das eleições, positivo para o PT-PMDB, não agradou a direita liberal-conservadora. Daí para o Golpe parlamentar de 2016, que levou a deposição da primeira mulher eleita democraticamente Presidente do Brasil, sem que nada fosse comprovado, foram dados passos largos.

Sob o tripé pátria (nacionalismo), religião (judaico-cristã) e família (nuclear), movimentos de cunho nazifascista e partidos políticos de direita contaram com apoio das Frentes Parlamentas, que emprestam caráter conservador ao Congresso Nacional.

Para se ter uma ideia da força deste mecanismo, torna-se necessário analisar a $55^{\mathrm{a}}$ Legislatura da Câmara Federal (2015-2018) que conta com as seguintes bancadas: (i) Frente Parlamentar Evangélica que, tendo como partido majoritário o PRB, seguido do DEM, PMDB e PSD, é composta por 203 signatários oriundos da Assembleia de Deus, Igreja Universal do Reino de Deus e Igreja Batista; seu presidente é João Campos (PRBGO) (ii) Frente Parlamentar Mista Católica Apostólica Romana conta com 215 membros, tendo o deputado Givaldo Carimbão (PROS-AL) como presidente. (iii) Frente Parlamentar em Defesa da Vida e da Família possui 236 signatários e seu presidente é Alan Rick, pastor evangélico, filiado ao PRB. (iv) Frente Parlamentar para a Liberdade Religiosa do Congresso possui 208 membros, tendo como presidente Celso Russomanno (PRB-SP), jornalista e católico (SILVEIRA, 2019, p.27).

Na realidade, o golpe de 2016 foi uma resposta à "crise orgânica do capital" (GRAMSCI, $1975^{7}$ apud DEL ROIO, 2018), pois que à frente da Presidência da República, Michel Temer coloca na pauta a Emenda Constitucional n ${ }^{\circ} 95$ e, na sequência, aprofunda as contrarreformas da educação, previdência social e trabalhista. Contrarreformas estas que têm sido elogiadas pelo Banco Mundial e OCDE. Isto quer dizer que, para o capital, o governo brasileiro tem sido responsável na execução da política macroeconômica por 
mediação do "ajuste justo" ", no que, sem sombra de dúvida, a educação cumpre papel preponderante, afinal a escola/a universidade são espaços privilegiados de formação dos intelectuais de diferentes camadas da sociedade.

\section{Continuidade e descontinuidade: $O$ que muda e o que permanece?}

A contrarreforma da educação básica, mediada pela Base Nacional Comum Curricular (BNCC), tem como protagonistas centrais a Confederação Nacional da Industria, Movimento Escola sem Partido (MESP) ${ }^{9}$ e o Movimento Todos Pela Base (MTB $)^{10}$. Entretanto, cada um a seu modo, disputou os espaços nos quais a BNCC deveria ser aprovada. O empresariado, assentado no tripé avaliação, meritocracia, e eficácia, defendia o Conselho Nacional de Educação (CNE) como espaço apropriado para ampliar os mecanismos de privatização e mercadorização da educação ${ }^{11}$; , enquanto o MESP pendia para o Congresso Nacional, cujo apoio das aliadas Frentes Parlamentas garantiria exterminar o suposto "exército organizado de militantes travestidos de professores" com sua a "contaminação político-ideológica" e "ideologia de gênero".

O reacionário MESP, ao pôr em xeque a competência oficial do MEC e do CNE, não logrou êxito ante o experiente empresariado brasileiro, que historicamente disputa os rumos da educação brasileira. Se as diferentes frações burguesas (indústria, serviços, agrária) disputam, permanente e internamente a (con)formação da classe trabalhadora, naquele momento viram-se diante da necessidade de unirem-se em torno do projeto burguês de longo prazo, junto ao Conselho Nacional de Secretários de Educação (CONSED) e à União Nacional dos Dirigentes Municipais de Educação (UNDIME), intelectuais coletivos legítimos, reconhecidos socialmente, e integrantes do MTB.

Mesmo assim, a guerra não estava perdida para o MESP, na medida em que o governo ilegítimo Michel Temer veio alargar o espaço para manifestações de grupos ultraconservadores (pequena burguesia e classe média) como resposta às ocupações de estudantes, apoiadas por professores, das escolas e universidades públicas e a outros movimentos populares que eclodiram no primeiro semestre de 2017. Assim, a caça às bruxas prossegue.

Conforme desvelamos em outro momento (SILVEIRA, 2019), logo após o golpe civilparlamentar de 2016, o MESP passa a ser um dos interlocutores do MEC tendo como alvo a (con)formação na infância que se manifesta na $3^{a}$ versão da BNCC, divulgada em dezembro de 2017. Esta trata apenas da educação infantil e do ensino fundamental, trazendo uma concepção reducionista do desenvolvimento humano, particularmente do desenvolvimento infantil, retomando o currículo tecnicista que vigorou no governo empresarial-militar.

O CNE, ao atender solicitação do MEC, não aprovou o tema "corpo, gênero e sexualidade nas tradições religiosas" sob o qual as escolas deveriam "discutir as distintas concepções de gênero e sexualidade segundo diferentes tradições religiosas e filosofias de vida". No lugar da temática sobre sexualidade, gênero e religião, entrou o eixo "princípios e valores éticos" que estabelece como umas das habilidades "reconhecer a coexistência como uma atitude ética de respeito à vida e à dignidade humana". Com esta medida, a 
violência de gênero e a discriminação sexual continuaram permeando o chão da escola e, por que não, se reproduzindo em larga escala na sociedade.

No que diz respeito à contrarreforma do ensino médio, sua proposta foi apresentada, ainda no governo Dilma Rousseff, no Projeto de Lei (PL) n 6.840/2013, de autoria do deputado Federal Reginaldo Lopes (PT/MG). No governo Temer, o PL foi transformado na Medida Provisória nº 746/2016, devido ao suposto caráter de urgência da reformulação da etapa final da educação básica e, na sequência, consubstanciado na Lei nº 13.415/2017.

Sendo a organização escolar, no Brasil, um sistema de relações dialéticas ${ }^{12}$, o nível médio de ensino apresenta caráter contraditório. De um lado, apresenta-se como etapa final da educação básica e, por esta razão, do ponto de vista da classe dominante, deve estreitar-se na profissionalização aligeirada (de curta duração) e fragmentada (apartada da formação geral); de outro, difunde-se como etapa de prosseguimento à educação superior. Esta contradição não é uma novidade do Brasil contemporâneo. No entanto, ela expressa o caráter de continuidade da política de Estado, presente nos mandatos de governo desde os 1990, respaldada por organismos supranacionais e empresariado brasileiro.

Como o papel do intelectual-professor é de crucial importância na execução de projetos de sociedade, toda e qualquer mudança na educação passa necessariamente pela formação e trabalho docentes. Não diferente, a aplicação da BNCC veio requerer a publicação da Resolução CNE/CP nº 2/2019, que define as Diretrizes Curriculares Nacionais para a Formação Inicial de Professores para a Educação Básica e na Base Nacional Comum para a Formação Inicial de Professores da Educação Básica (BNC-Formação), na direção contrária das lutas de entidades de classe, como a ANFOPE, que lutam pela formação do educador de caráter sócio-histórico tendo por base a docência.

No que diz respeito à universidade, ela vem passando por um dos momentos mais críticos de sua história, no que concerne aos cortes de verba o que incide mediata e imediatamente sobre sua autonomia. Esta vem sendo entendida, desde os anos 1990, como um atributo de um movimento de aproximação ao setor empresarial, de modo a universidade diversificar sua fonte de financiamento, o que, obviamente, põe em risco a pesquisa desinteressada (pesquisa básica) e a formação do pensamento crítico. À medida que o governo, em curso, promove incessantemente cortes de verbas (custeio, capital, bolsas de estudo) empurra o financiamento da universidade para as mãos do empresariado e organizações sociais como prevê o Programa Future-se. Ao mesmo tempo, retira de seus sujeitos históricos escolher, entre sues pares, quem os dirige. A Medida Provisória n ${ }^{\circ}$ 914/2019 remonta ao governo empresarial-militar, ao abrir a possibilidade de o Presidente da República acatar ou não o nome mais votado da lista tríplice de candidatos eleitos interna e democraticamente nas universidades, centros e institutos federais de educação profissional, cientifica e tecnológica e Colégio Dom Pedro II.

De índole fascista ${ }^{13}$ e entreguista, o governo Bolsonaro mantém e restaura. "O aspecto restauração, por sua vez, não consegue contemplar a dimensão da hegemonia civil, pelo contrário, estimulando a conflitualidade no seio dos grupos socais subalternos, induz uma permanente guerra civil de varável intensidade" (DEL ROIO, 2018, p. 237). 
Devido à crise de hegemonia interna, no plano microeconômico, as expropriações (primária e secundária), agora levadas à cabo por mãos de ferro, disseminam a violência e o pânico e parecem não ter fim, pondo em risco a capacidade de reprodução da força de trabalho, aliada à destruição ambiental. No plano macroeconômico, segue com "o ajuste justo", mantendo o câmbio flutuante para incentivar as exportações brasileiras, a taxa da inflação "controlada", a taxa de juros baixa para altos investidores, enquanto no setor de empréstimo/crédito voltado para os trabalhadores ela se mantém inalterada/alta. Ao mesmo tempo, dá prosseguimento ao Programa Nacional de Desestatização, instituído por lei em 1997 ao privatizar cinco empresas estatais antes de completar um ano de governo.

\section{Considerações finais}

Ao longo do texto, buscamos evidenciar os traços de continuidade e descontinuidade entre os sucessivos mandatos de governos neoliberais, no Brasil, e suas implicações no campo educacional.

Apesar de algumas modificações no discurso e nas ações, é possível perceber que — apesar das disputas intraburguesas ora de caráter conservador, ora conciliatório e, mais recentemente, reacionário, e entre estas e classe trabalhadora, em torno dos projetos de sociedade e de educação — há uma continuidade no processo de perda dos direitos sociais e subjetivos.

Os ataques à autonomia administrativa, financeira e didático-pedagógicos da escola/universidade pública, a desqualificação do papel escolar e universitário e, sobretudo, do intelectual-professor são mediados e mediações pelos/dos processos de privatização e mercadorização da educação. À medida que se privatizam o espaço público, a transmissão e a produção do conhecimento, a classe trabalhadora tornase cada mais desprovida dos meios e instrumentos que possibilitam a passagem da consciência fragmentada da realidade à consciência crítica da totalidade. Urge, portanto, a reversão deste quadro.

O atual momento da crise orgânica do capital radicaliza o movimento dialético entre barbárie e socialismo. Contudo, a revolução de base socialista, como ressalta Santos (2018), não é resultado da espoliação, antes ela é resultado da exploração e expropriação dos trabalhadores e de sua consciência de classe. A revolução contra o capital, mais do que nunca, requer a organização da classe trabalhadora, em escala global, que, por sua vez, passa pela luta por uma educação pública, gratuita de qualidade, socialmente referenciada, tendo por base a formação do sujeito para o trabalho coletivo. Adiante!

\section{Referências}

BARATA-MOURA, José. Materialismo e subjetividade: estudos em torno de Marx. Lisboa, Pt: Editorial Avante!, 1998.

BARRETO, Marcos P. Educação e meio ambiente: a urgência de uma utopia vermelha e verde. In: BATISTA, Eraldo Leme et al. Escola sem partido ou a escola da mordaça e do partido único a serviço do capital [e-Book]. Minas Gerais, Uberlândia: Navegando publicações, 2019. DOI: 10.29388/ 978-85-53111-27-5-0-f.17-48. Disponível em: https://www.editoranavegando.com/livro-escola-sempartido. 
BATISTA, Eraldo Leme et al. Escola sem partido ou a escola da mordaça e do partido único a serviço do capital [e-Book]. Minas Gerais, Uberlândia: Navegando publicações, 2019. DOI: 10.29388/ 978-85-53111-27-5-0-f.17-48. Disponível em: https://www.editoranavegando.com/livro-escola-sempartido.

BRUM, Argemiro. O desenvolvimento econômico. Petrópolis: Vozes, 1982.

DEL ROIO, Marcos. Gramsci e a emancipação do subalterno. São Paulo: Ed. Unesp, 2018.

DEMIER, Felipe. A revolta a favor da ordem: a ofensiva da oposição de direita. In: DEMIER, Felipe; HAEVELER, Rejane. A onda conservadora: ensaios sobre os atuais tempos sombrios no Brasil. Rio de Janeiro: Mauad, 2016. pp.51-56.

FERNANDES, Florestan. Capitalismo dependente e classes sociais na América Latina. Rio de Janeiro: Zahar editores, 1973.

FONTES, Virgínia. A transformação dos meios de existência em capital - expropriações, mercado e propriedade. In: BOSCHETTI, Ivanete (Org). Expropriação e direitos no capitalismo. São Paulo, Cortez Editora, 2018, pp. 17-61.

FONTES, Virgínia. O Brasil e o capita-imperialismo: teoria e história. Rio de Janeiro: EPSJV/Editora UFRJ, 2010.

GRAMSCI, Antonio. Cadernos do Cárcere, v.5. Il Risorgimento - notas sobre a história da Itália. 2.ed. Rio de Janeiro: Civilização Brasileira, 2002.

GRAMSCI, Antonio. Cadernos do cárcere. v.3. Maquiavel; Notas sobre o Estado e a política. 3.ed. Rio de Janeiro: Civilização Brasileira, 2007.

IANNI, Otávio. Dialética e capitalismo. Petrópolis: Vozes, 1982.

IANNI, Otávio. Imperialismo na América Latina. 2. ed. Rio de Janeiro: Civilização Brasileira, 1988.

INSTITUTO BRASILEIRO DE GEOGRAFIA E ESTATÍSTICA (IBGE). Síntese de indicadores sociais: uma análise das condições de vida da população brasileira: 2019. Rio de Janeiro: IBGE: Coordenação de População e Indicadores Sociais, 2019.

MARINI, Ruy Mauro. Dialética da dependência. Petrópolis, RJ: Vozes; Buenos Aires: CLASO, 2000.

MARINI, Ruy Mauro. Dos momentos en la integración latinoamericana. Arquivo Rui Mauro Marini: Canadá, 1993. Disponível em: http://www.marini-escritos.unam.mx/021_integracion_es.htm.

MARINI, Ruy Mauro. La acumulación capitalista mundial y el subimperialismo. In: Cuadernos Políticos n. 12, Ediciones Era, México, abr./jun., 1977. Disponível em: http://www.marini-escritos.unam.mx.

OLIVEIRA, Francisco. Hegemonia às avessas. In: OLIVEIRA, Francisco et al. Hegemonia às avessas: economia, política, e cultura na era da servidão financeira. São Paulo: Boitempo, 2010, pp. 21-27.

RANCIÉRE, Jacques. Ódio à democracia. São Paulo: Boitempo, 2014.

SANTOS, Theothônio dos. Socialismo ou fascismo: o novo caráter da dependência e o dilema latinoamericano. Florianópolis, SC: insular 2018.

SANTOS, Theotonio dos. La teoria de la dependência: Um balance histórico y teórico. In: SEGKEKA, Francisco Lopes (ed.). Los rell de la globalizacion. Ensayos em homenage a Theotonio dos Santos. Tomo I. Caracas: UNESCO, 1998.

SCHWARZ, Roberto. Valor Intelectual. Prefácio com preguntas. In: OLIVEIRA, Francisco. Crítica à razão dualista - O ornitorrinco. São Paulo: Boitempo, 2003, pp. 11-23.

SILVEIRA, Zuleide S. Onda Conservadora: o emergente Movimento Escola Sem Partido. In: BATISTA, Eraldo Leme; ORSO, Paulino José; LUCENA, Carlos (Orgs.). Escola sem partido ou a escola da mordaça e do partido único a serviço do capital [e-Book]. Minas Gerais, Uberlândia: Navegando publicações, 2019. DOI: 10.29388/ 978-85-53111-27-5-0-f.17-48. Disponível em:

https://www.editoranavegando.com/livro-escola-sem-partido 


\section{SILVEIRA, Zuleide Simas da. Concepções de educação tecnológica na reforma da educação superior: finalidades, continuidades, e rupturas - estudo comparado Brasil e Portugal (1995-2010).} Niterói, 2011. 445f. Tese (Doutorado em Educação). Faculdade de Educação, Universidade Federal Fluminense, Niterói, 2011.

\section{Referências}

${ }^{1}$ Professora da Faculdade de Educação da Universidade Federal Fluminense (FEUFF). Professora do Programa de Pós-Gradução em Educação da Universidade Federal Fluminense (UFF). Doutora e Mestre em Educação pela Universidade Federal Fluminense (UFF). Líder do Grupo de Pesquisa Estado, Trabalho, Educação e Desenvolvimento: a contribuição do pensamento latino-americano (GPETED) http://dgp.cnpq.br/dgp/espelhogrupo/239641. Editora-Chefe da Movimentorevista de educação do programa de pós-graduação em educação e da faculdade de educação da UFF. CV: http://lattes.cnpq.br/8037763146233564 Orcid: http://orcid.org/0000-0002-7855-2484 E-mail: zuleidesilveira@gmail.com

2 Vale lembrar que a contrarreforma da previdência não é uma novidade do governo Bolsonaro. Nos mandatos FHC foi aprovada a Ementa Constitucional $n^{\circ}$ 20, que mudou as regras para a aposentadoria: o tempo de serviço do trabalhador deixa de ser contabilizado, cedendo lugar para o tempo de contribuição ao Instituto Nacional de Seguro Social (INSS): no mínimo, 35 anos para os homens e 30 para as mulheres, tendo por base o, então, criado fator previdenciário. A seguir, no governo Lula da Silva, foi aprovada a Emenda Constitucional $n^{\circ} 41$, que alterou o cálculo para a aposentadoria dos servidores públicos federais, que deixam de receber o salário integral. A remuneração passou a ser calculada de acordo com a média da contribuição ao Plano de Seguridade Social - uma contribuição que sempre foi diferenciada, superior e separada da contribuição ao INSS. Foi neste período de governo que se criou um teto para aposentadorias dos servidores estaduais e federais. Também foi no governo Lula da Silva que, dos servidores aposentados se passou a descontar, em folha, 11\% de contribuição previdenciária. No governo Dilma Rousseff, foi sancionada a fórmula no 85/95 Progressiva, que leva em conta a expectativa de vida do trabalhador. Apresentada como alternativa ao fator previdenciário, a fórmula representa entre a soma da idade do trabalhador e o tempo de contribuição, cujo total, sendo igual ao número de pontos exigidos, é o salário integral.

3 As siglas e correlatos mandatos significam, respectivamente, Partido da Reconstrução Nacional (Collor de Mello), Partido Social Democrata Brasileiro e Partido da Frente Liberal (FHC), Partido dos Trabalhadores (Lula da Silva), Partido dos Trabalhadores e Partido do Movimento Democrático Brasileiro (Dilma Rousseff) e Partido Social Liberal (Bolsonaro). Recentemente, Jair Bolsonaro desligou-se do PSL, alegando incongruências internas e, por conseguinte, criar nova legenda, intitulada Aliança pelo Brasil. Todavia, trata-se de uma estratégia para lanças candidatos, a ele vinculados político-ideologicamente, às eleições municipais de 2020. O programa do mais novo partido reacionário (não consolidado formalmente) gira em torno de cinco eixos: (i) Respeito a Deus e à religião; (ii)) Respeito à memória, à identidade e à cultura do povo brasileiro; (iii) Defesa da vida, da legítima defesa, da família e da infância; (iv) Garantia da ordem, da representação política e da segurança; e (v) Defesa do livre mercado, da propriedade privada e do trabalho. Para mais detalhes, ver o site oficial, disponível em: https://www.aliancapelobrasil.com.br/

${ }^{4}$ Dados do IBGE (2019) revelam que, em 2018, o percentual de estudantes que frequentavam instituições públicas na educação infantil, ensino fundamental, médio e superior era de $74,3 \%, 82,3 \%, 87,0 \%$ e $25,8 \%$, respectivamente. Assim, a rede privada de ensino de graduação atendeu a maioria dos estudantes, o que representa $74,2 \%$.

5 Fontes: Jornal Extra Classe [on line], disponível em: https://www.extraclasse.org.br/educacao/2019/05/ataques-asuniversidades-federais-favorecem-grupos-privados/

ViaCarreira [on line], disponível em: https://viacarreira.com/grupos-brasileiros-de-educacao-superior/ ;

6 Apropriamo-nos, aqui, de Schwarz (1992 apud SCHWARZ, 2003).

${ }_{7}$ GRAMSCI, Antonio. Quaderni del carcere. Ed, de Valentino Gerratana. Torino: Eunaudi, 1975. 4v.

8 Referimo-nos ao Relatório do Banco Mundial, intitulado Um Ajuste Justo - Análise da Eficiência e Equidade do Gasto Público no Brasil (2019). Cf. https://www.worldbank.org/pt/country/brazil/publication/brazil-expenditure-reviewreport?cid=EXT WBEmailShare EXT

${ }^{9}$ Para mais detalhes ver BATISTA et al, 2019.

${ }^{10}$ Movimento pela Base. Disponível em: http://movimentopelabase.org.br/quem-somos/

11 De modo agilizar a aprovação dos documentos legais, o governo Temer alterou a composição do CNE. Cf. http://portal.mec.gov.br/conselho-nacional-de-educacao/cne-quem-e-quem.

12 Apropriamo-nos, aqui, de Barata-Moura (1998), ao analisar o sistema como dialética de relações, em Marx. Nesta perspectiva, não concordamos com a formulação que afirma existir uma dualidade estrutural-educacional, segundo a divisão da sociedade em duas classes fundamentais, na medida em que se firma em sistema fechado. Se assim a sociedade se estrutura, ela não é estática, mas pulsante. A natureza ontológica do processo social é dialética, contraditória e mediatizada, um todo articulado. À medida que a sociedade capitalista se desenvolve e se complexifica, a escola/educação marcadamente dual-estruturalista (em sua aparência, mas não em sua essência) de fins do século XIX e início do XX, já não faz sentido. Aliás esta é uma discussão superada pela crítica aos reprodutivistas. O fenômeno escolar/educacional é multiplamente determinado e apresenta-se como unidade do diverso. É exatamente pelo fato de ele ser unidade do diverso que se organiza, sob o trabalho abstrato, em torno da formação do corpo do "trabalhador coletivo", como "capacidade de trabalho socialmente combinada" (2004a; 2004b). Tal formação se realiza material e dialeticamente em diversificada rede de instituições, organizada segundo os ramos do saber, oferta e tempo de duração dos cursos, que se complementam mutuamente. Não há, pois, dualidade estrutural-educacional até mesmo quando se desconsidera as frações das classes fundamentais e as contradições inerentes ao campo educacional. A formação do corpo do trabalhador coletivo 
é a manifestação de um todo articulado, pois qualifica, ao mesmo tempo, "um [que] trabalha mais com as mãos, outro mais com a cabeça, este como diretor (manager. Ing.), engenheiro (engineer. Ing.), técnico, etc., aquele como capataz (overlook. Ing.) aquele outro como operário manual ou até como simples servente" (MARX, 2004b).

13 Para tal classificação baseamo-nos nas características do fascismo (dependente) apontadas por Santos (2018, p. 86-95).

Recebido em: 01.12.2019

Aprovado em: 21.04.2020 